\title{
Patologia de neonatos bovinos originados por meio da técnica de transferência nuclear de células somáticas - clonagem
}

\author{
Pathology of bovine neonates generated by somatic cell nuclear transfer - cloning \\ Caio Rodrigues dos SANTOS $^{1}$; Fabrizio GRANDI ${ }^{1}$; Maria Angélica MIGLINO²; Flávio Vieira \\ MEIRELLES $^{3}$; Paulo César MAIORKA ${ }^{1}$
}

${ }^{1}$ Departamento de Patologia da Faculdade de Medicina Veterinária e Zootecnia da Universidade de São Paulo, São Paulo-SP ${ }^{2}$ Departamento de Cirurgia da Faculdade de Medicina Veterinária e Zootecnia da Universidade de São Paulo, São Paulo-SP ${ }^{3}$ Faculdade de Zootecnia e Engenharia de Alimentos da Universidade de São Paulo, Pirassununga-SP

\begin{abstract}
Resumo
Os mecanismos de morte em animais clonados a partir de células somáticas são poucos elucidados. Malformações de órgãos, alterações de tamanho e peso desses animais foram anomalias já descritas, porém em casos isolados. Desse modo, estudos nos níveis anatomo e histopatológicos são de suma importância para ajudar a compreensão dos fatores responsáveis pelos altos índices de insucessos com a utilização da TNCS (transferência nuclear de células somáticas). Assim, o presente trabalho foi realizado com o objetivo de descrever, por meio de exames anatomopatológicos, as alterações presentes em um grupo de animais gerados por TNCS, que vieram a óbito entre 1 e 19 dias de vida. Esse experimento foi realizado entre os anos de 2004 e 2008 na fazenda Tambaú, cidade de Tambaú, Estado de São Paulo. No total foram gerados 21 animais da raça Nelore (Bos indicus), sendo que 11 vieram a óbito e dez apresentaram boa evolução clínica no período perinatal. Foram realizadas as necropsias dos animais e posterior análise histopatológica de tecidos alterados. Esse estudo mostrou alta prevalência de alterações cardiopulmonares, que provavelmente foram determinantes nos mecanismos de morte dos animais. Dentre essas alterações a hipertensão pulmonar e modificações hemodinâmicas diagnosticadas através do exame histopatológico foram as mais frequentes.
\end{abstract}

Palavras-chave: Neonatos bovinos. Clonagem. Patologia. Transferência nuclear.

\begin{abstract}
The death mechanisms in cloned animals are not well elucidated. There are few cases describing organ malformation, size and weight alterations in these animals. Pathologic studies are necessary to understand the high level of unsuccessful results using the NTSC (nuclear transfer somatic cell) technique. The present study was carried out to describe alterations present in a group of animals generated by NTSC technique that deceased between 0 to 19 days of life, using anatomopathologic examination. This experiment was conducted at Tambaú Farm in São Paulo State between years 2004 and 2008. Initially there were twenty one Nelore breed Bos indicus animals, but 11 of them deceased and ten survived and showed satisfactory clinical evolution in perinatal period. Animals necropsies and histopathologic analyses where performed. The results revealed a high prevalence of cardiopulmonary alterations, which were predominantly lung hypertension and hemodynamic profile changes, revealed by histopathologic analyses.
\end{abstract}

Keywords: Neonates bovine. Cloned. Pathology. Nuclear transfer.

\section{Introdução}

A clonagem ou técnica de transferência nuclear é uma biotécnica que permite a geração de um organismo genomicamente semelhante a outro. Para tanto, é utilizado o núcleo de uma célula somática ou embrionária de interesse, o qual é transferido posteriormente para um oócito previamente enucleado ${ }^{1}$.

Inúmeras aplicações da técnica de transferência nuclear são hipotetizadas na pecuária, na medicina humana e na ciência básica². O sucesso da clonagem de animais confirma a utilidade da TNCS para o pro-

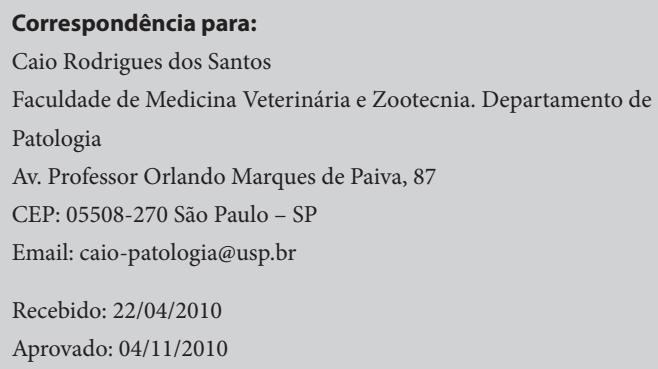


pósito de expansão clonal de animais de produção. Há também um crescente interesse na reprodução de indivíduos com perfil de excelência e alta produtividade, ou com características que se queira manter ou imprimir em um rebanho ${ }^{3}$, além da conservação de espécies em risco de extinção ${ }^{4}$. Outra aplicação seria a produção de animais geneticamente modificados, os quais podem ser utilizados como biorreatores ou doadores de órgãos para xenotransplantação ${ }^{3,5}$.

Em 1997 foi anunciado o nascimento do primeiro mamífero clonado por meio da técnica de TNCS: uma ovelha gerada a partir de núcleo doador proveniente da glândula mamária de um adulto de seis anos de idade $^{6}$. Após o nascimento da ovelha Dolly, vários outros mamíferos de diferentes espécies foram gerados pelo procedimento de transferência nuclear. Após 13 anos do nascimento da ovelha Dolly, grande parte dos animais gerados por TNCS ainda vem a óbito antes de completar seis meses de idade ${ }^{7}$. As alterações encontradas nos animais clonados foram tidas como incidentes isolados e foram alocadas dentro da "síndrome do bezerro grande", a qual ocorre em associação com a manipulação do embrião e é caracterizada por um tamanho exagerado do animal ao nascimento, além de outras anormalidades morfológicas e fenotípicas ${ }^{8}$.

As anormalidades fenotípicas encontradas nos clones, que raramente acometem animais não clones, revelam que há necessidade de uma investigação anatomopatológica dos animais gerados por esta técnica. A proporção elevada de animais que vem a óbito in utero após a transferência dos embriões clones para as mães de aluguel, e a alta porcentagem de má formação em animais neonatos sugere que o procedimento de transferência nuclear pode estar relacionado ao desenvolvimento destas anomalias. Logo, esses achados demonstram o valor de estudos anatomopatológicos detalhados de embriões, fetos, neonatos e animais adultos clonados. Muitos trabalhos estão sendo publicados sobre o método de transferência nuclear e respectiva maturação do oócito ${ }^{9}$. Publicações recentes afirmam que estas etapas do processo de clonagem são responsáveis pelos insucessos na produção de animais clonados ${ }^{1}$.

\section{Material e Método}

O procedimento de TNCS foi conduzido na fazenda Tambaú, localizada no município de Tambaú, estado de São Paulo, durante o período de 2004 a 2008. Nesse período foram gerados, no total, 21 animais oriundos de TNCS. Para esse procedimento foram utilizadas células somáticas de um animal adulto doador do patrimônio genético. Nesse estudo o tipo celular empregado foi o fibroblasto. Dentre os 21 animais gerados, 11 vieram a óbito ainda no período perinatal (Quadro 1) e dez apresentaram um bom estado de saúde. Os animais que vieram a óbito foram encaminhados para o Laboratório de Patologia Animal da Faculdade de Medicina Veterinária e Zootecnia da Universidade de São Paulo, onde foi realizado o exame necroscópico.

Durante o exame necroscópico foram selecionados fragmentos de pulmão, coração, fígado, linfonodos, baço e timo, os quais foram fixados em solução de formaldeído a $10 \%$, incluídos em parafinas e seccionadas no micrótomo com espessura de $5 \mu \mathrm{m}$ e posteriormente coradas pela técnica Hematoxilina Eosina.

\section{Resultados}

\section{Necropsia}

Ao exame externo dos animais, foram evidenciadas as seguintes alterações: as mucosas de orifícios naturais apresentaram padrão cianótico presente em 100\% dos animais necropsiados. Os linfonodos superficiais apresentaram moderada linfoadenomegalia, alteração esta visualizada em todos os animais necropsiados. Dentre os animais, 30,7\% apresentaram alterações no aparelho locomotor, caracterizadas por aumento na dimensão das articulações metacarpofalangeanas esquerda e direita (Figura 1-A), acompanhada de ede- 


\begin{tabular}{|c|l|l|l|l|c|}
\hline \multirow{2}{*}{${\text { Clone }{ }^{\circ}}$} & Raça & Sexo & $\begin{array}{c}\text { Data do } \\
\text { nascimento }\end{array}$ & Data de óbito & Data da necropsia \\
\hline 1 & Nelore & Fêmea & $07 / 09 / 04$ & $22 / 09 / 04$ & $22 / 09 / 04$ \\
\hline 2 & Nelore & Fêmea & $04 / 10 / 04$ & $09 / 10 / 04$ & $09 / 10 / 04$ \\
\hline 3 & Nelore & Macho & $04 / 03 / 05$ & $07 / 03 / 05$ & $07 / 03 / 05$ \\
\hline 4 & Nelore & Macho & $12 / 03 / 05$ & $13 / 03 / 05$ & $14 / 03 / 05$ \\
\hline 5 & Nelore & Macho & $18 / 03 / 05$ & $18 / 03 / 05$ & $21 / 03 / 05$ \\
\hline 6 & Nelore & Fêmea & $03 / 12 / 05$ & $04 / 12 / 05$ & $05 / 12 / 05$ \\
\hline 7 & Nelore & Fêmea & $26 / 12 / 05$ & $26 / 12 / 05$ & $26 / 12 / 05$ \\
\hline 8 & Nelore & Fêmea & $26 / 12 / 05$ & $06 / 01 / 06$ & $06 / 01 / 06$ \\
\hline 9 & Nelore & Fêmea & $09 / 06 / 06$ & $19 / 06 / 06$ & $19 / 06 / 06$ \\
\hline 10 & Nelore & Fêmea & $28 / 01 / 07$ & $06 / 02 / 07$ & $07 / 02 / 07$ \\
\hline 11 & Nelore & Macho & $17 / 05 / 07$ & $20 / 05 / 07$ & $21 / 05 / 07$ \\
\hline
\end{tabular}

Quadro 1 - Dados referentes aos animais necropsiados no período de 2004 a 2008 - São Paulo - 2010
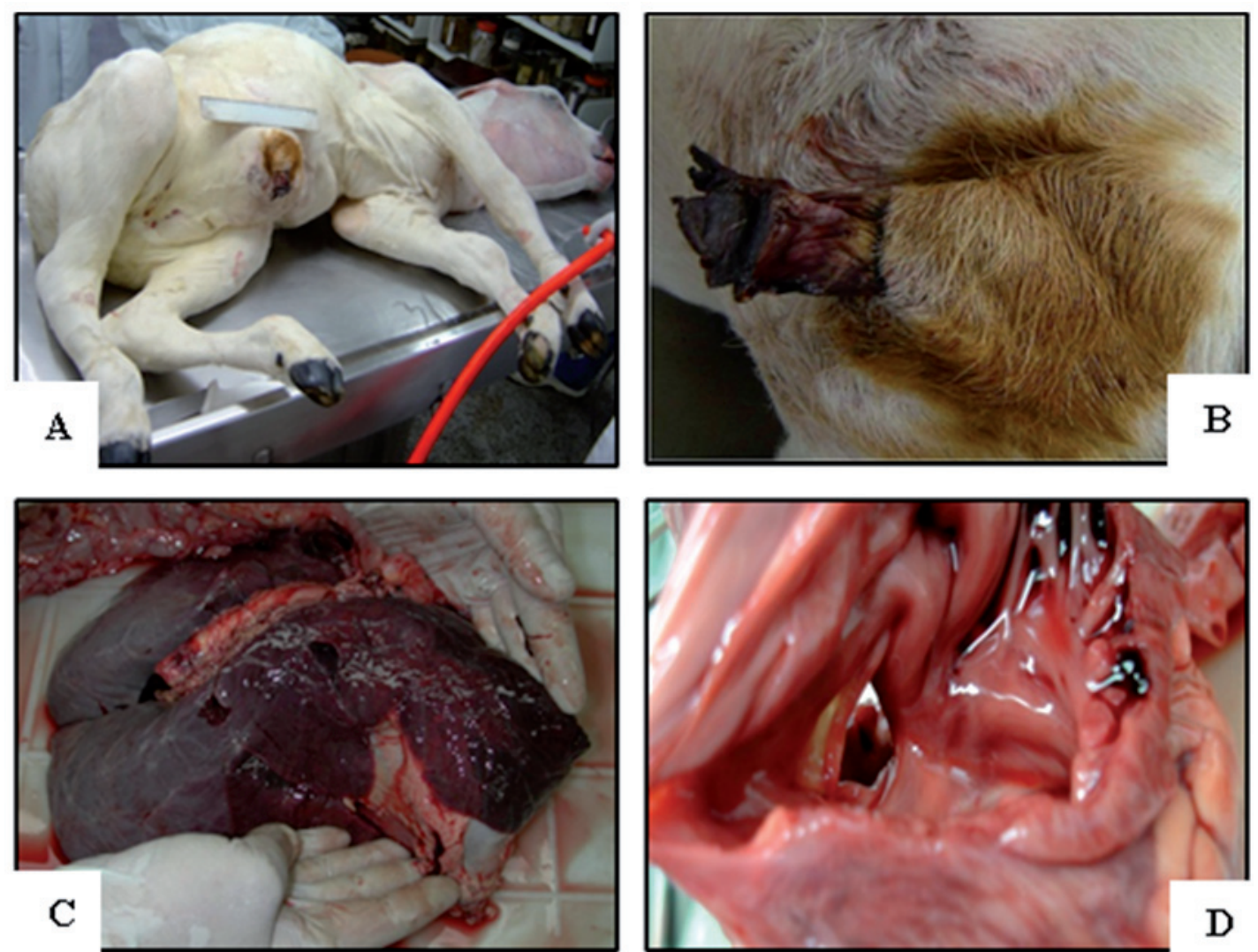

Figura 1 - (A) Aumento das dimensões das articulações metacarpofalangeana e metatarsofalangeana. (B) Cicatrização ineficiente do cordão umbilical. (C) Atelectasia Pulmonar. (D) Defeito do Septo Interventricular

ma subcutâneo, consistência crepitante à palpação e perda de arquitetura tecidual. Já no membro pélvico houve aumento na dimensão das articulações meta- tarsofalangeana esquerda e direita. Uma cicatrização incompleta do cordão umbilical (Figura 1-B) pôde ser observada em todos os animais necropsiados. 
A abertura da cavidade abdominal revelou a presença de moderada efusão peritoneal de aspecto límpido e coloração levemente acastanhada sem evidências de exsudato, observado em todos os animais. Os órgãos abdominais não apresentaram alterações na topografia, respeitando a sintopia e delimitações anatômicas.

A cavidade torácica, ao contrário da cavidade abdominal apresentou efusão abundante de fibrina, caracterizando um hidrotórax sero-fibrinoso, sendo que tal alteração foi constatada em 100\% dos animais necropsiados. Os órgãos torácicos não apresentaram alterações em sua respectiva topografia.

\section{Sistema Respiratório}

Alterações no sistema respiratório foram evidenciadas em todos os animais necropsiados, embora cada animal apresentasse particularidades como localização e extensão e intensidades diferentes. Todos os animais necropsiados apresentaram líquido de aspecto aerado e com presença de mecônio proveniente de aspiração distribuído por toda traqueia. As alterações pulmonares apresentaram o mesmo padrão e a mesma distribuição em todos os animais necropsiados. Puderam ser observados enfisema pulmonar difuso em todos os lobos pulmonares, atelectasia pulmonar difusa e edema pulmonar (Figura 1-C), o que foi confirmado pelo extravasamento de grande quantidade de líquido seroso do parênquima pulmonar após o corte. Constatou-se também presença de hemorragia e congestão pulmonar em $23 \%$ dos animais necropsiados, visto que o parênquima pulmonar apresentou ao corte extravasamento de líquido sero-hemorrágico.

\section{Sistema Cardiovascular}

O coração e os grandes vasos apresentavam malformações e alterações no desenvolvimento. Cistos hemáticos de aproximadamente $5 \mathrm{~mm}$ de diâmetro com os maiores medindo cerca de $2 \mathrm{~cm}$ de diâmetro foram evidenciados em valvas tricúspide e mitral, em alta severidade, o que destoa do padrão considerado normal para bezerros neonatos, sendo esta alteração constatada em 46,1\% dos animais necropsiados.
Em 46,1\% dos animais houve persistência do forame oval e defeito do septo interventricular (Figura 1-D); $7,6 \%$ dos animais necropsiados apresentou patência de ducto arterial, dilatação do ventrículo direito, justaposição de músculos papilares, inserção errônea de cordas tendíneas à parede lateral do ventrículo direito e aderência de valvas tricúspide e mitral na parede cardíaca; $15,3 \%$ dos animais necropsiados apresentou espessamento de trabécula septo marginal esquerda, hipertrofia excêntrica de miocárdio ventricular direito e esquerdo e inserção de cordas tendíneas em septo interventricular do ventrículo esquerdo. Outras alterações como sufusões e víbices em miocárdios direito e esquerdo, dilatação de grau leve de ventrículo direito, espessamento de cúspide septal da valva mitral, justaposição de músculos papilares e inserção de cordas tendíneas à parede ventricular lateral direita e justaposição de valvas tricúspide e mitral à parede cardíaca lateral direita e esquerda, respectivamente também foram observadas.

\section{Sistema Digestório}

Em 15,3\% dos animais houve lesões em serosa ruminal e abomasal, que foram caracterizadas por hemorragia com aspecto de sufusões e víbices distribuídas difusamente pelos órgãos. Em 23\% dos animais necropsiados foi observado, por toda extensão do intestino delgado, hiperemia da mucosa intestinal acompanhada por conteúdo de aspecto mucoso e coloração amarelada. Hemorragias com aspecto de sufusões evidenciadas na serosa do intestino delgado e intestino grosso. Alterações hepáticas estavam presentes em $46,1 \%$ dos animais necropsiados, caracterizadas por congestão hepática, parênquima com coloração levemente amarelada e com os bordos irregulares.

\section{Sistema Urinário}

Apenas 7,6\% dos animais necropsiados apresentaram lesões renais. A cápsula renal apresentava áreas de adesões no parênquima adjacente, os cálices renais estavam dilatados e as pirâmides renais do rim direito apresentaram coloração vermelho escura. Na superfí- 
cie renal puderam ser observadas lesões puntiformes de coloração esbranquiçada, distribuídas de forma difusa nos rins direito e esquerdo. Ao corte, ambos os rins apresentaram coloração acastanhada no córtex e coloração avermelhada na medula.

\section{Hemolinfático}

O timo apresentou severa hipoplasia. O que foi observado em $84,6 \%$ dos animais necropsiados. Além dos linfonodos superficiais já citados, 100\% dos animais necropsiados apresentaram linfoadenomegalia do linfonodo mesentérico.

\section{Histopatologia}

\section{Pulmão}

Amostras de pulmões coletados durante a necropsia apresentaram as mesmas alterações histológicas em todos os animais. Puderam ser observadas áreas de consolidação pulmonar caracterizando atelectasia pulmonar (Figura 2-A), as regiões atelectásicas predominavam na região periférica dos lobos pulmonares. Material homogêneo e de coloração eosinofilica foi evidenciado preenchendo o interior de espaços alveolares. Esse padrão de alteração é compatível com edema pulmonar. Trombos em organização encontravam-se aderidos à camada íntima de artérias e arteríolas e apresentavam coloração eosinofilica em seus interiores e intenso sequestro de células polimorfonucleares. Pequena porcentagem de alvéolos apresentou presença de mecônio caracterizado por um material amorfo e acastanhado preenchendo todo espaço alveolar, proveniente de aspiração. O que pode ter desencadeado um processo de pneumonia por aspiração (Figura 2-B).
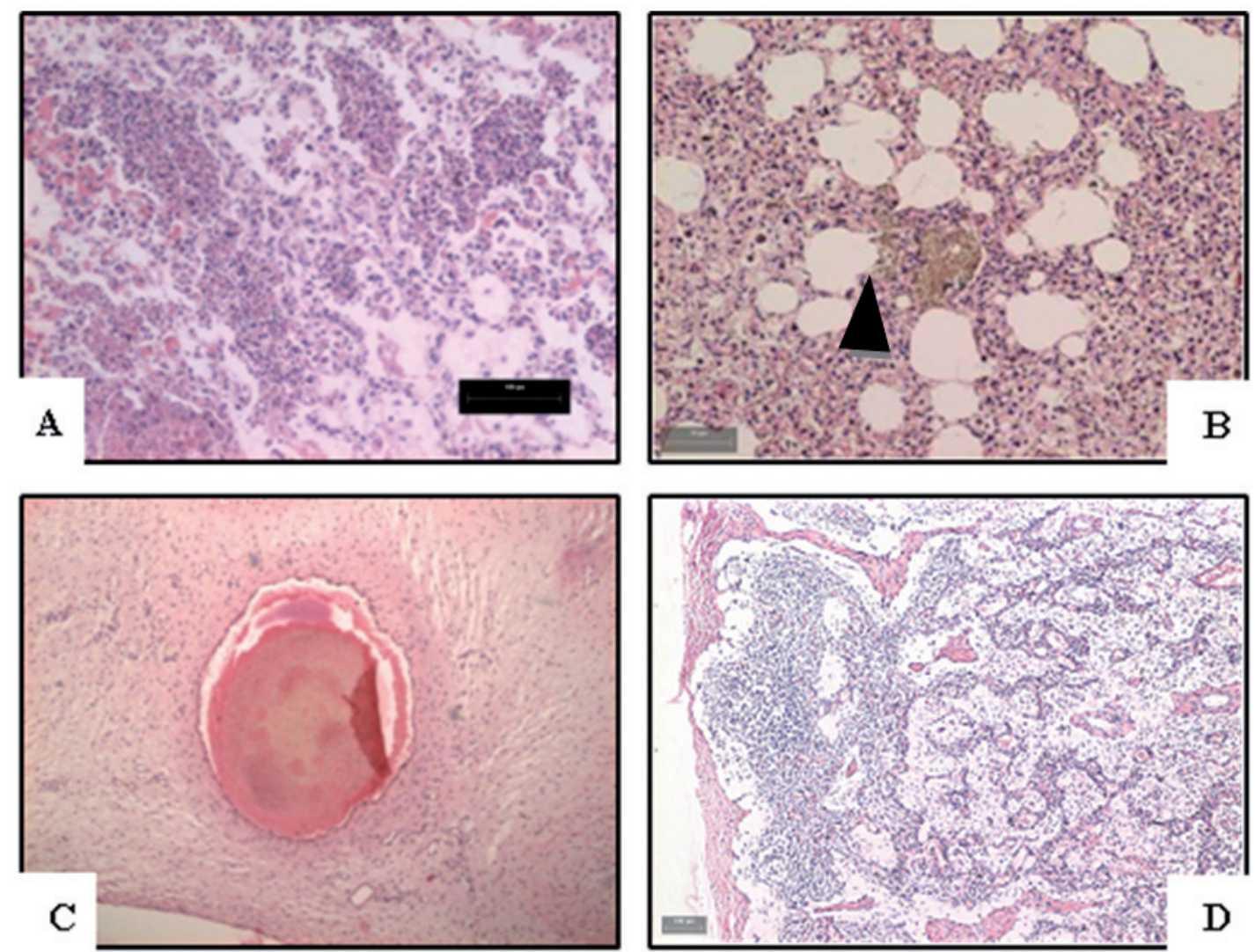

Figura 2 - (A) Foto micrografia (H\&E escala em barra $=100 \mu \mathrm{m}$ ) Atelectasia Pulmonar, (B) Foto micrografia $(H \& E$ escala em barra $=70 \mu \mathrm{m})$ Pneumonia por aspiração, seta evidenciando a presença de mecôneo, $(\mathrm{C})$ Foto micrografia $(\mathrm{H} \& \mathrm{E}$ escala em barra $=100 \mu \mathrm{m}$ ) Cisto Hemático em região valvular, (D) Foto micrografia $(H \& E$ escala em barra $=100 \mu \mathrm{m})$ Timo: Rarefação Linfoide e perda do padrão lobular 


\section{Coração}

Para a realização do exame histopatológico do coração, foram selecionadas áreas da região valvular a fim de visualizar a formação dos cistos encontrados no exame necroscópico. Os cistos apresentavam contornos bem definidos e região central fortemente eosinofilica (Figura 2-C).

\section{Fígado}

O exame necroscópico evidenciou fígados com um aspecto amarelado a acastanhado. Esse padrão de lesão sugere um quadro de degeneração hepática; ao exame microscópico foi constatada a presença de degeneração com padrão macro e micro vesicular. Os hepatócitos estavam edemaciados e com presença de vacúolos no interior do citoplasma, os núcleos, devido à redução do espaço citoplasmático, foram deslocados para a periferia da célula.

\section{Linfonodos e Timo}

Os linfonodos superficiais e mesentérico apresentaram severa rarefação linfoide, houve perda da arquitetura tecidual com a ausência da relação córtico-medular, sendo que grande quantidade de macrófagos estava distribuída difusamente pelo parênquima do órgão. $\mathrm{Na}$ periferia notou-se a presença de intenso edema.

O parênquima do timo caracterizou-se por severa rarefação linfoide e intenso edema e congestão vascular (Figura 2-D).

\section{Discussão}

A taxa de sucesso no desenvolvimento a termo e sem perdas gestacionais de um animal clone ainda é bastante baixa. Diversas alterações patológicas descritas nesse trabalho são responsáveis pelo alto índice de óbitos envolvendo animais clonados ${ }^{10}$.

Dentre as cardiopatias observadas, cistos hemáticos presentes nas regiões valvulares são comumente encontradas em animais sadios, porém a disposição e o volume dos cistos encontrados nesse estudo diferem das estruturas citadas na literatura e tida como nor- mais. Esses cistos anormais podem causar insuficiência valvular, corroborando com a morte do animal. Cardiopatias foram relatadas por Garry et al. ${ }^{11}$, em seu estudo, no qual 40 bezerros derivados de células embrionárias foram clonados e desses, oito animais vieram a óbito e foram necropsiados. $\mathrm{Na}$ necropsia puderam ser observadas alterações cardíacas, tais como dilatação e arredondamento do coração acompanhado de efusões pleurais. De maneira semelhante, Hill et al. ${ }^{12}$ relataram lesões cardíacas, como dilatação do ventrículo direito com espessamento bilateral de parede ventricular, associadas ao aumento do diâmetro da artéria pulmonar e ducto arterial patente. Além destas cardiopatias descritas por Garry et al. ${ }^{11}$ e Hill et al. ${ }^{12}$, outras cardiopatias e alterações do desenvolvimento foram observadas no presente estudo, que podem estar envolvidas na alta taxa de mortalidade.

Diversas áreas de atelectasia foram evidenciadas. Nesse sentido Hill et al. ${ }^{12}$ suspeitaram que uma das prováveis causas da incompleta expansão pulmonar apresentada em um dos bezerros clonados pudesse ser a deficiência de surfactante. A deficiência de surfactante pode estar relacionada com a diminuição na produção deste pelos pneumócitos tipo II e outra hipótese poderia ser uma diluição do mesmo pela grande quantidade de líquido amniótico inspirado pelos animais. Além da atelectasia observada nesse estudo, trombos pulmonares, edema pulmonar e hipertensão pulmonar provavelmente também corroboraram para a instalação de um quadro de insuficiência respiratória nos animais clones.

Renard et al. ${ }^{13}$ descreveram alterações hemolinfáticas, sendo que os animais com os quais trabalharam apresentaram severa hipoplasia tímica. No presente estudo, além da hipoplasia tímica marcante, observamos ao exame macroscópico linfadenomegalia generalizada. Porém, ao exame microscópico, constatou-se que o aumento no tamanho dos linfonodos foi decorrente de edemas localizados na região cortical desses órgãos. 


\section{Conclusão}

A realização desse trabalho pode vir a colaborar para a elucidação dos processos patológicos responsáveis pela alta taxa de insucesso na TNCS, sendo esse o primeiro trabalho brasileiro sobre patologia de neonatos bovinos clonados. As principais alterações responsáveis pela morte dos animais foram cardiopulmonares. Dentre as cardiopatias presentes, podemos ressaltar as malformações, responsáveis por causar insuficiência cardíaca e por sua vez insuficiência respiratória secundária. As lesões pulmonares primárias, representadas pela incapacidade de expansão alveo-

\section{Referências}

1. CAMPBELL, K. H.; MCWHIR, J.; RITCHIE, W. A.; WILMUT, I. Sheep cloned by nuclear transfer from a cultured cell line. Nature, v. 380, p. 64-66, 1996.

2. MEIRELLES, F. V.; BIRGEL, E. H.; PERECIN, F.; BERTOLINI, M.; TRALDI, A. S.; PIMENTEL, J. R.; KOMNINOU, E. R.; SANGALLI, J. R.; NETO, P. F.; NUNES, M. T.; POGLIANI, F. C.; MEIRELlES, F. D.; KUBRUSLY, F. S.; VANNUCCHI, C. I.; SILVA, L. C. Delivery of cloned offspring: experience in Zebu cattle (Bos indicus). Reproduction, Fertility and Development, v. 22, n. 1, p. 88-97, 2010.

3.EDWARDS, J. L.; SCHRICK, F. N.; MCCRACKEN, M. D.; VAN AMNSTEL, S. R.; HOPKINS, F. M. Cloning adult farm animals: a review of the possibilities and problems associated with somatic cell nuclear transfer. American Journal of Reproductive Immunology, v. 50, p. 113-123, 2003.

4.LANZAQ, R. P.; CIBELLI, J. B.; FABER, D.; SWEENEY, R. W.; HENDERSON, B.; NEVALA, W.; WEST, M. D.; WETTSTEIN, P. J. Cloned cattle can be healthy and normal. Science, v. 294, p. 1893-1894, 2001.

5. BUHLER, L. H. Xenotransplatation literature update marchapril. Xenotransplatation, v. 11, n. 4, p. 383-386, 2004.

6. WILMUT, I.; BEAUJEAN, N.; DE SOUZA, P. A.; DNNYES, A.; KING, T. J.; PATERSON, L. A.; WELLS, D. N.; YOUNG, L. E. Somatic cell nuclear transfer. Nature, v. 419, p. 583586,2002 lar, somada à severa hipertensão decorrente da insuficiência cardíaca, corroboraram para o alto índice de mortes observadas nesse estudo. Tanto as alterações cardíacas como as alterações pulmonares evidenciadas aqui, precisam de um estudo mais detalhado, visto que $46,1 \%$ dos animais necropsiados apresentaram algum tipo de malformação cardíaca. Todos os animais examinados nesse estudo apresentaram incompleta ou nenhuma expansão alveolar. Com isso se pode deduzir que a alta taxa de mortalidade de animais clonados esteja fortemente relacionada a causas cardiorrespiratórias.

7. CHAVATTE-PALMER, P.; REMY, D.; CORDONNIER, N.; RICHAR, C.; ISSENMAN, H. Health status of cloned cattle at different ages. Cloning Stem Cells, v. 6, p. 94-100, 2004.

8. FARIN, P. W.; PIEDRAHITA, J. A.; FARIN, C. E. Errors in development of fetuses and placentas from in vitro produced bovine embryos. Theriogenology, v. 65, n. 1, p. 178-191, 2006.

9.SUI, J.; MA, X.; GAO, Z.; HU, Y.; SUI, J.; HUANG, W.; ZAN, L.; DOU, Z. Program optimization for bovine somatic cells nuclear transfer. Chinese Journal of Biotechnology, v. 25, n. 9, p. 1424-1432, 2009.

10.SANTOS, C. R. Patologia de neonatos bovinos clonados. 2008. 101 f. Dissertação (Mestrado) - Faculdade de Medicina Veterinária e Zootecnia, Universidade de São Paulo, São Paulo, 2008 .

11.GARRY, F. B.; ADAMS, R.; MCCANN, J. P.; ODDE, K. G. Postnatal, characteristics of calves produced by nuclear transfer cloning. Theriogenology, v. 45, p. 141-152, 1996.

12.HILL, J. R.; WINGER, Q. A.; LONG, C. R.; LOONEY, C. R.; THOMPSON, J. A. Development rates of male bovine nuclear transfer embryos derived from adult and fetal cells. Biology of Reproduction, v. 62, n. 5, p. 1135-1140, 2000.

13.RENARD, J. P.; CHASTANT, S.; CHESNE, P.; RICHARD, C.; MARCHAL, J.; CORDONNIER, N.; CHAVATTE, P.; VIGNON, X. Lymphoid hipoplasia and somatic cloning. Lancet, v. 352, n. 9163, p. 1489-1491, 1999. 